\title{
The role(s) of student voice in I4-19 education policy reform: reflections on consultation and participation
}

\author{
Jannette Elwood*
}

School of Education, Queen's University Belfast, Belfast, Northern Ireland

(Received 30 September 2012; final version received 28 March 2013)

\begin{abstract}
Certain policy areas with considerable impact on young people's educational experiences and achievements, notably assessment and qualifications, do not involve consultation with young people to any meaningful extent. Findings from a national study, which included focus groups with 243 students in the 14-19 phase, are presented with respect to student consultation and participation in such policy areas. A lack of meaningful consultation regarding what students see as 'higher level' policy agendas was found (such as qualifications provision, choice or structure). Students are therefore 'voiceless' in relation to major qualifications reforms.
\end{abstract}

Keywords: 14-19 education; student voice; consultation; qualifications; policy reform

\section{Policy contexts - 14-19 educational reform and student voice}

Over recent years, the 14-19 phase of education within the UK has become a major policy arena that has witnessed a proliferation of educational reforms with the aim of standards, increasing choice and opportunity and improving education generally for all young people. In England, the past Labour government made the 14-19 phase of education and training a priority area and the present coalition government (Conservative and Liberal Democrat) is following suit with considerable resources and policy attention focused on the 14+stage of education. Significant reform initiatives at this phase, their political orientations, associated policy drivers and impacts have been the focus of much analysis and discussion (for example see Baird et al. 20I I; Hodgson and Spours 20l la, 20l lb and associated papers within the special issue of this journal 9(2) 20II). The main consensus within these analyses is that such major reform programmes are overly ambitious, and tend to set in motion a raft of policy changes that end up being visited upon schools and colleges all at once with considerable, and not always wholly desirable, impacts. Subsequently, such programmes suffer from being too extensive and diverse, with significant repercussions for 14-19 provision. The present policy context for 14-19 education is no less complex or stable than preceding ones. What remains constant is a proliferation of educational initiatives being pressed upon schools and colleges (ultimately teachers and students) all at the same time with exceptional speed.

One common priority across recent and immediate educational policy programmes is that of qualifications reform. The centrepiece of the Labour reforms between 2002 and 2010 was the creation of a qualification entitlement that was structured into four pathways or routes to qualifications that young people could pursue from the age of 14 onwards

\footnotetext{
*Email: j.elwood@qub.ac.uk
} 
(DCSF 2008). These qualifications pathways had emerged out of earlier, significant changes to academic and vocational qualifications for 16- to 19-year-olds under the banner of Curriculum 2000 (Hodgson and Spours 2003). Over this time, there was a raft of initiatives that allowed for major structural changes to well-established qualifications (modular instead of linear examinations, resits, the AS level, the $A^{*}$ grade) as well as the introduction of new qualifications to bridge the academic-vocational divide (Diplomas) that were deemed equivalent with more mainstream qualifications. Likewise, with the commencement of the Coalition government from May 2010 onwards, qualifications reform has emerged as a key driver to achieve educational policy priorities. However, not surprisingly given differing political and ideological positions, a very different focus and rationale underpins the basis of current reforms. The Education Act (DfE 2013a) lays out a framework for an educational programme that has moved away from any distinctive 14-19 phase and has created more distance between vocational and academic pathways (Higham and Yeomans 20l I). Also, there has been the removal of those qualifications (Diplomas) not deemed to equate with the government's desire for 'quality, rigour and challenge' (Gibb 20I0); the urgent and extensive reform of $A$ levels and GCSEs'; and the significant reduction in the number of vocational qualifications deemed of suitable quality to be accredited (Elwood 2012; Wolf 20II). The fabric of these changes is contextualised within an education system that is, on the one hand, allowing more freedom to schools and colleges in relation to management, governance and curriculum arrangements while on the other, exerting more control over examinations and qualifications than has been seen for some time (HoC 20I2).

This proliferation of policy reform in 14-19 education has been carried out within the context, and growing popularity, of public consultation with regard to policy development. Indeed, there has been a gradual acceptance over recent years that it is good practice to consult key stakeholders immediately affected by policy change or implementation (Cook 2002). An extension of this general consultation model with adult stakeholders has been the growing involvement of children and young people in policy decision-making (Middleton 2006; Sinclair 2004; Tisdall 2008). This has been reflected within a range of national children's strategies that include initiatives to involve children in policy deliberations as well as statutory obligations on public authorities to consult children about policies that affect them directly (Harris 2009). Many of these initiatives are presented under the banner of 'student voice'; a collective label that has been used to promote as good practice the inclusion of students' participation in local, contextual decision-making. Indeed, the Labour educational reforms saw the promise of student voice as a crucial dimension to the successful implementation of many of its 14-19 initiatives at the local and national level:

There is no group whose view is more important in terms of the 14-19 reform programme than the young people themselves. That is why it is critical that the student voice is heard, at both local and national level, and that the planning and delivery of 14-19 reforms can respond to the ideas and energy of I4-19 year olds. (DCSF 2008, 6I, para 4.26).

This position reflected a wider, growing practice of consulting children and young people more generally about their schooling (Flutter and Rudduck 2004; Osler 2010). It also demonstrated the prescriptive levels of statutory requirements for student consultation and participation (Bragg 2007) and the extent to which the inclusion of 'student voice' was influencing evaluation activities of educational institutions and inspection programmes more generally (Lodge 2005).

However, while the practice of consultation has grown to be commonplace in many reform initiatives, the degree to which it is carried out effectively and productively, either 
with adults or with children and young people, has been contested (Bragg 2007; Cook 2002) and its often tokenistic nature has been seen as detrimental to its success. In the present policy landscape, there is no direct policy driver linked to the inclusion of consultation with students to deliver new educational reforms; many in-roads that were made into treating children and young people as equal stakeholders and decision-makers with regard to education policy have stalled; and the status of such previous legislation is uncertain (Fleming 2012). However, present governments are no less responsible than previous ones for adherence to international treaties on human and child rights ratified by the UK. As Lundy (2007) reminds us, consulting with, and the participation of, children and young people on all matters that affect them, including educational provision, is a legally binding obligation on government. However, we have a situation where it is less explicit as to how children and young people should be involved in, or consulted upon, education policy development (Payne 2012). With respect to qualifications reform, any instances of meaningful engagement with children and young people about this significant and important phase of their education unfortunately continue to be rare (Elwood and Lundy 2010). At present, within the qualifications arena in England, there tends to be pattern of pronouncement rather than of consultation, and, where consultation happens, the tendency is to consult with adult stakeholders on implementation of the policy (design, timing, etc.) rather than the policy itself (BBC 20I2).

This paper presents research that took the inclusion of students' voice in the implementation of 14-19 educational reform to the heart of its design. We were interested to map whether students were being consulted about educational provision and policy, as good practice might dictate. If students were being consulted, we were interested in how they were being consulted and what they were being consulted about and also whether their views had any influence on the development and planning of reforms in their institutions. More specifically, we set out to consult them about qualifications reform and their views in this neglected area. These views form the substance of the data that follow. To contextualise the data presented, the paper begins with an overview of the student voice and participation literature in order to show the complexities and the contestations of the area but also to illustrate some of the complacencies about those areas deemed suitable by adults for student consultation. As the data show, there are some educational areas, such as qualifications and examinations, where high-level decisions are taken which render students 'voiceless' in these contexts.

\section{Student voice in educational reform}

Cook-Sather (2006) detailed the emergence of research and reform activities, under the collective banner of 'student voice', that have repositioned the worth of students' unique perspectives on teaching, learning and schooling. Such a repositioning, she argued, demands not only that students' insights warrant attention but that they also need to be responded to by adults and that students 'should be afforded opportunities to actively shape their education' (360) as well as be considered equal stakeholders in influencing policy and reform decisions. She goes on to suggest (Cook-Sather 2006, 366-367) that one of the most positive aspects of the inclusion of student voice in research and reform activities is an associated 'cultural shift' with its 'insistence on altering dominant power imbalances between adults and young people' that ultimately demands seeing students as 'knowers and actors' in determining their own goals, and adults as active listeners to improve relationships and pedagogical practice. Lundy (2007) further argued that the inclusion of student voice is about more than just good practice - it is about children's rights. She is particular in arguing that fully embracing children and young people as key stakeholders in their educational experience and provision is 
rarely positioned by government in terms of children's rights. Under Article 12 of the United Nations Convention on the Right of the Child (UNCRC), not only must the government consult children and young people in all matters that affect them (including education), they must also support children's contribution to decision-making as well as listen to their views in constructive ways (Lundy 2007).

However, any true adherence to including student voice in educational reform is complex and problematic in many ways, not least in determining what these activities mean in relation to children and young people, and the ways in which such engagement suffers the same limitations and difficulties as similar processes with adults (Tisddall and Davis 2004; Cook 2002). Cook's $(2002,521)$ research showed that consultation can be deeply problematic as often the model implemented is characterised as tokenistic, unrepresentative and unengaging. She suggested that consultation ends up being a series of 'comments, compliments and complaints' about existing practices rather than constructive engagement about new directions. Many authors across a variety of jurisdictions and a range of settings have also detailed similar limitations and flaws with regard to consultation and participation processes with children and have outlined concerns about the effectiveness of such processes as they become more prevalent (Bragg 2007; Cook-Sather 2002, 2006; Rudduck and Fielding 2006; Fleming 2012; Halsey et al. 2006; Tisdall 2008). Such processes fail to achieve the tangible outcomes and impact on policy-making initially envisaged. Fleming $(2012,6)$ has also suggested that failures arise from a blurring of the processes and the outcomes of participation, with adults often making participation a 'restricted and organisational construct'. To get the best out of the 'student voice', Sinclair (2004) argues for moving beyond 'one-off or isolated consultations' to a position where students' participation is 'firmly embedded within organisational cultures and structures for decision-making' (2004, II6).

Many problems also arise through the ways in which voice is positioned and indeed selected within organisations which most likely means that those being consulted are only a small proportion of the total student group (Fleming 2012). Cook-Sather (2006) further argued that assumptions about a single 'student voice' ultimately deny diversity and difference in students' needs and opinions and hide those hierarchies of power and privilege within and across student groups that can elevate certain students' views beyond those of others. The complications of authorising student voice can be further compounded by the challenges for adults of listening to things they do not wish to hear, especially perhaps criticism of teachers, as well as the possibility that adults 'glamorize student voice' (ibid. 369) in order to meet particular institutional and national targets. In authorising student voice, Cook-Sather (2002) argued that we have to be prepared to share authority about educational matters with students and to rethink who is authoritative about the impact and effects of educational policies and practice as they are played out within institutions and policy arenas.

\section{Students' perspectives on education}

Flutter and Rudduck (2004) argued that the key element in any investigations concerned with the improvement of teaching and learning must be the teachers and learners themselves; this type of first-hand evidence is essential to understanding how improvements might be brought about. From this work, key themes emerged about pupils' perspectives on their own lives, their experiences of schooling and how the two interconnect: the management of time, friendships and the social aspects of learning; the powerful influence of peer relationships on students' sense of self-worth; and the impact on learning and performance. Flutter and Rudduck (2004) acknowledge that the aspects that shape and form 
young people's positive identities as learners and achievers are complex and are formed as much from their lived experiences outside of the school environment as from within. However, consulting with pupils about their experiences and what would make a significant difference to them can become a valuable tool for educational institutions in identifying and addressing key issues affecting learning and achievement. The work of Osler (20I0) identified similar themes with older students who also expressed the desire to be listened to and to have their views respected by teachers. Students from this study were also more aware of, and vociferous about, the wider political contexts in which they, their teachers and their educational institutions must operate.

However, a key area of reform within which students' views are less likely to be sought is assessment, in its broadest sense, but examinations and qualifications in particular. Elwood and Lundy (2010) argued that lack of engagement with students about these matters is surprising given the significant role assessment plays in students' educational experiences and the amount of political and academic concern about its adverse consequences on students' overall experiences of schooling (HoC 2008). Elwood and Lundy (op. cit.) further suggested that there is a limited history of children's involvement in decision-making within the field of assessment at any level and that even with numerous assessment policy initiatives implemented since the ratification of the UNCRC by the UK, we have yet to see the involvement of children and young people as a matter of course in decision-making with regard to national assessment programmes. This lack of 'student voice' is indeed surprising given that so much of educational reform includes debates about suitable assessment regimes and the role they should play in enhancing and improving the educational achievement of all students. Thus, the data presented in this paper aim to address this lack of 'student voice' in this arena. Significant findings emerged from the research that specifically set out to engage students in discussions about the qualifications programmes and their views on national policies of reform in these areas.

\section{Methodology and data}

The data presented in this paper are from a study funded by the Department of Children, Schools and Families (DCSF) through the Qualifications and Curriculum Development Agency (QCDA) (hereafter referred to as the CReSt study) to consider the impact of 14-19 educational reforms on schools and colleges in England (Baird et al. 201 ${ }^{2}$ ). The research had two phases: phase I comprised two baseline studies that mapped the impact of educational policy within local contexts for a sample of 52 educational institutions (mainstream and special provision) prior to the beginning of Labour's reform programme (Gorard et al. 2008; QCDA 2009); phase 2 aimed to track the impact of the multiple reform agenda within the same 52 educational institutions between 2009 and 2014 (Baird et al. 201 I). The foci of phase two were the complementary and competing effects of mass policy changes upon educational institutions and their stakeholders.

In the first year of Phase $2(2009 / 10)$, 18 case studies were selected from the 52 educational institutions involved. The cases were geographically spread across England and situated equally within urban/city, suburban/small town and rural locations. The sample included: II-16 schools (5), II-19 schools (I), 13-19 schools (1), 16-19 sixth form colleges (3), academies (I), FE colleges (2), independent schools (I), special education centres (3) and specialist colleges (I). Three-day case study visits were carried out which included interviews and focus groups conducted with a number of key stakeholders (Principals (or deputies), curriculum managers, governors, students, teachers and parents). Forty-five student focus groups were conducted across these sites; 17 with Year-II students (aged 15/I6), 18 with Year-I 3 students (aged I7/ 
18), and 10 with Year-10 (age 14/15) and Year-12 (age 16/17) students if the institution was either an II-16 school or post-16/FE college. A total of 243 young people were selected by their institutions to be involved. Students were engaged in a range of topics for discussion: their experiences of the 14-19 reforms; whether their schools consulted them on institutional-level policy reforms; their opportunities within their institutions to choose qualifications and educational pathways; and their experience of teaching and learning. The qualitative data from the student focus groups were transcribed and coded using the structures of focus group schedules as well as emerging issues from the students. The primary data were analysed both deductively, driven by theory and concepts of policy reform and student engagement within each individual case, and then inductively, driven by ideas emerging from the data across all 18 centres. Computer software (NVIVO 8) was used in both the management of the data and in relation to analytical procedures. The data-set is a large and rich collection of students' views, perspectives and opinions on a range of areas that impact on their experience of 14-19 education.

To reflect the complexities of consultation and participation with students, a deliberate, threefold methodological stance was taken: (i) to ascertain to what degree students are consulted by their institutions and if so, what aspects of their educational experiences are they consulted about; (ii) to engage students about particular aspects of their educational experience that are rarely discussed with young people; and (iii) to specifically consult with young people on 14-19 reforms. This paper focuses upon findings from three of the 23 primary level codes used to analyse the focus group data, notably: 'voice, participation and consultation'; 'curricular and assessment changes and pressures'; and 'views on 14-19 reforms'. Key themes relating to young people's experiences of consultation and participation and their views on qualifications, examinations and assessment were extracted from these three codes and are explored below.

\section{Consultation with students - practices and impact}

Overall, responses showed that generally students were consulted in one form or another about aspects of their school experience. Issues for consultation varied highly across type of issue and local context and setting. While students were generally positive about being able to 'have a say', they were concerned about the limitations of some of these consultations. Students considered whether their educational institutions, teachers and other managers are perhaps going through the motions of consultation and not really listening - a sense of telling rather than discussing. They suggested that consultation enabled them to have a say, but not a very influential one:

Interviewer: So does [your centre] ever consult you on its policies?

SI: They kind of pretend to listen but half the time they say they're going to listen to the students but they don't.

S2: They don't do it as much as they put across they will.

S3: Yeah it's that thing of like [teachers] want our opinion on things but we don't have that much power and it's more just to keep us happy ... (Year-II focus group)

Students reported that their views and opinions were normally channelled through some sort of student body, be it student councils, forums, student representatives or student 
group. These were constituted in different ways either through elections, volunteers or selection. All such groups crossed different teaching years or other organisational structures. The processes associated with how these consultation forums worked were also similar across institutions: students consulting peers either through surveys, emails, feedback sheets, suggestion boxes and/or face-to-face meetings; students voicing opinions and views about matters significant to them and/or any structural and social issues within the institution; and student views gathered, collated and fed back to teachers and/or senior managers or to a dedicated member of staff. There were varying views as to how effective and transparent these mechanisms for consultation are, given a lack of clarity about how peers are elected or selected to student councils. Such views were further compounded by a sense of not knowing how student consultations are used, whether their feedback has made any difference and whether teachers are actually interested in what students have to say. One example of where students did think they had influence emerged from discussions about having direct access to teachers to discuss issues of significance to them and where support was forthcoming to address these issues:

I think we have got quite a lot of influence because now we have got these golden groups meetings, [with] one teacher, out of the lesson, talking through what we need help with but also asking questions about how are teachers helping us. So we can report it to our teacher and then that information gets passed around [other] teachers - it kind of allows everyone to pass information along the chain and it does get our views across. (Year-II focus group)

Students suggested that such one-to-one discussion sessions may be an effective way to be consulted so that their views might have some impact. However, participants were also quite aware that feeding back their views to teachers does not automatically mean that changes will take place. They recognised that their institutions cannot do all that they would wish them to do, but students would rather be consulted than not:

SI: I would say they [the college] make an effort to change things but I think students have to make an effort too.

S2: There's a lot of things that they can't do as well though isn't there? (Year-12 focus group)

Students indicated that they were more likely to be consulted about classroom processes, approaches to teaching and ways of learning than about the content of their learning (e.g. curriculum, subject knowledge, assessment, etc.). They are often required to complete evaluations of teaching and learning at certain times during the year, either at the end of a module or at the end of a course which focus on types of teaching, learning and learning styles, enjoyment of learning, teaching and learning resources, etc. Such evaluations were seen as constructive, with students welcoming being involved in teachers' improvement of their own practice. However, such processes were also seen as vehicles for monitoring teachers rather than seeking genuine understanding of students' views about teaching and learning:

SI: We have those questionnaires at the end of term that ask do we like the way the teachers teach

S4: And how often they mark your work and stuff like that. How often they check your work.

SI: I think it is more to monitor the teachers than seeing what we think is best. (Year- 13 focus group) 
As Cook (2002) and Rudduck and Fielding (2006) have argued, models of consultation (with adults or children) are often static and end up lacking credibility to those engaged with them. These sentiments are reflected in the data reported here. Students' views also tended to reflect Cook-Sather's (2006) considerations of the unbalanced power relations between adults and young people in educational settings with not all attempts at listening to students' voices being wholly constructive or effective of change. Lundy (2007) was critical of such practices which, under the banner of 'student voice', actually only provide minimal opportunities for young people's views to be taken into consideration. The data suggest that students understand they cannot change everything that they may be consulted about in their institutions, and their views cannot have undue weight above those of others, but they did reflect Lundy's call to be listened to constructively and that they be informed as to how their views have been acted upon.

\section{Student consultation and participation - affecting change}

As a consequence of student representation and consultation, a variety of changes had occurred within the institutions, some of which proved to be significant to students. Examples included improved learning and physical environments and enhancement of the day-to-day quality of students' experiences in attending their school or college. Thus, changes for the better across a number of activities were disclosed by participants. For example, variety shows and entertainments for families; the reduction of litter around the school/college site; the introduction of cheaper and healthier food menus; the adaptation of school rules which included students' views and concerns; the introduction of school uniform which improved their image of themselves and their institution; improved access for disabled students; and cleaner and better spaces for them to congregate which improved their day-to-day environment were given as example changes:

SI: ... via the council, we can make suggested improvements to try and make the school better as well as benefit us ... So like we never used to have rugby posts or anything, so we said that not long ago and they have been put up, and re-laying the Astroturf in the tennis courts and that's all been done. It used to look scruffy, like the fencing, and now it's quite smart, to be proud of...

S2: and that's important, because we spend our out-of-lesson time there, so we want it to look good and to get the most out of it. We don't want it to be old and out-dated.

S3: It's got to be something that appeals to you and makes you like want to get out of bed in the morning. You're not going to want to turn up if it's all like freezing cold classrooms and tables are falling apart. (Year-II focus group)

The degree of positive responses from student participants across the focus groups indicated a notable level of student consultation within the case study institutions, with them embracing, to some extent, the inclusion of 'student voice' within private, intra-institutional policy/practice arenas (Fleming 20I2). To a certain degree, the data from this study show that students see their institutions working with them to make improvements, but frustrations tended to emerge around clear areas of school/college life and decision-making about which students were not consulted. These areas also extended into national policy decisionmaking outside of institutional boundaries; public policy arenas in which students did not feel they had a voice. It is to one of these particular areas - qualifications and examinations that I turn to next. 


\section{Student consultation and participation in 'real decision-making' - what students think}

Students suggested that consultation was effective on one level - 'just what happens in schools', but less effective on issues of 'real decision-making'. Students identified 'real decisionmaking' issues as: aspects of governance of their institutions; what was taught as much as how it was taught and the curriculum offer; options for qualifications pathways; and how their learning was structured. They felt these were much bigger issues that affected their day-to-day lives in school and would welcome opportunities to discuss these with teachers and others beyond their institutions. Such considerations reflect those of Cross (2012) who found that the more centrally an issue effected a young people, the less likely they were to be consulted about it and that participation of young people was only attempted in low risk (to adult authority) domains. Recent considerations of children's rights and assessment more generally (Elwood and Lundy 2010) have emphasised that examinations, qualifications and how young people are assessed seem to be outside 'low risk' areas. The data from the CReST study support this view. When students were asked if they were specifically consulted on policy issues and choices made around qualifications or examinations, the general response was no:

\section{SI: I think that is the only thing that we don't really get a say in. (Year-I I focus group)}

Participants indicated that the tendency was for them to be told what was happening, when changes had been made or decisions taken in relation to qualifications. Generally, they do not get 'any chance to contribute' to the choices made for them with regard to assessment practices or types of qualifications chosen. Examples that emerged from the data centred around syllabus choices, examination boards used, placement in ability sets and allocation to teaching groups. There was a sense that choices within these realms were not available to students and that decisions were fixed:

SI: Teachers tell us after the change has been made ... they told us how they [government] will bring in $A^{*}$, and that they changed the specification.

S2: I think they [teachers] discuss it between themselves. I think they should bring in more student opinion ... I kind of dread it, because it's not them who's doing exams, it's us ... they should get more opinion from us than between themselves. (Year-13 focus group)

Reasons offered regarding why they were excluded from decision-making in these areas were varied. Students suggested that age and maturity might influence who could be asked for a view, with perhaps key aspects of curriculum and assessment policies being more constructively shared with older students. Respondents also considered whether students were best placed to have an input into these areas or contribute to such decisions, which were seen as 'higher level' than perhaps other aspects of school/college life. Furthermore, students considered that teachers would think that students would want things to be easier for them if they had input into such discussions:

S2: If we had more of a say then obviously we would want A Levels to be easier (laughter...) and, obviously, that drops the bar from what they want. (Year- 12 focus group)

However, when students were consulted about national assessment programmes, they had constructive and informed opinions about the ways in which their educational 
experiences are affected by qualifications structures, high-stakes examinations and having to deal with significant amounts of assessment and testing more generally. Students were aware of the value of qualifications and the role that they play within education and society more generally, but concern was expressed about the degree of assessment that takes place and how young people are constantly preparing for some aspect of formal assessment:

SI: Especially with GCSE subjects being modular, from about year 10 you're doing exams January, June, January, June, January, June ... we're doing exams for 4 years straight from the age of what 14. (Year-13 focus group)

Such responses were also contextualised by the pressure they feel under to succeed. Students were concerned that not only, in their opinion, were examinations getting harder, and good grades more difficult to obtain, but that assessment and examinations dictated everything they did; for this generation of students, there was 'pressure from the word go'.

In terms of qualifications policy reforms, students were keen to emphasise that having a choice of assessment components (e.g. exams and coursework) was a matter or fairness and equity as not all students liked exams and/or coursework and that the best type of assessment allowed for both. Likewise, they were keen to retain a modular approach to examinations and to allow resits if necessary, seeing such processes as indicators of progress and where effort should be placed as well as opportunities to improve on poor performances. It is perhaps interesting to reflect that what students saw as positive aspects of current examinations structures and design (coursework, modularity and resits) are exactly those components detailed to be removed from future qualifications for 16- and 18-year-olds, if current government plans come to fruition in 2017 (DfE 2012, 20I3b).

Students expressed much concern about the whole context of reform of examinations and qualifications, especially as they felt their qualifications were being devalued and that changes were being introduced without evaluation or piloting, and that they ultimately bore the brunt of mistakes and/or system failures. This they saw as too high a price, given the difficulties of obtaining university places and the need to obtain higher and higher grades in order to achieve their goals. Participants were anxious to express disagreement with media debates about examinations being too easy, or that standards were falling because pass rates were rising. Students considered it insulting that their successes were being downgraded by the 'standards are falling' rhetoric and felt that perhaps they were victims, rather than beneficiaries, of grade inflation as they felt examinations were just as difficult as in previous years and that they had to work even harder to obtain similar goals as their predecessors:

SI: we are under a lot of pressure to get good grades and $A^{*}$ just increases this, it will become what is required to get into university and if you don't get it people might look down on you.

S2: yeah, its $\left[\mathrm{A}^{*}\right]$ too fine a gradation really, it's introduced to help distinguish people but it makes it harder to get a place and also they could be missing good people who just miss out ... (Year-13 focus group)

With respect of new examinations being introduced without piloting, participants felt that their future successes could be 'messed up' because of failures by government and/or awarding bodies to prepare correctly or to miss vital steps in the preparation of examination papers that ultimately impacts on students in significant and negative ways:

SI: It's like the paper that was released in the January exams... it was because it was a new exam specification, and friends came away... with Ds. and Es. It's really messed up their whole future 
... they now can't become a doctor or whatever it is they wanted to do. So the exams need to be tested before they're put out. (Year-13 focus group)

Thus, students clearly had significant views to offer about assessments and qualifications that play a considerable role in their lives. A significant aspect to emerge from the data was that students considered they could be supported by their teachers in voicing their views on examinations and qualifications reform to those whose responsibility is to develop and deliver them (e.g. the awarding bodies across the UK, Ofqual, government, etc.). Students suggested that teachers could be 'enablers of students' voices', to support their views being heard by significant stakeholders on issues of concern, such as, the structures within examinations and the availability of different types of assessments. However, students did recognise that changes to specifications, syllabuses and so on are hard for teachers to understand and implement, as they are for students - that everyone (students and their teachers) is "learning in the dark'. Students greatly appreciated what their teachers do for them. However, there was a significant sense of disappointment that they are always told about changes to syllabuses, specifications and qualifications rather than being consulted prior to decisions being made.

\section{Discussion and reflections}

The goal of the research was to engage with government policy of the day that specified the inclusion of 'student voice' in understanding development and implementation of major national educational reforms. As such, students feel included to a certain degree in shaping certain aspects of their educational experience locally, what Fleming (20I2) has termed the private spheres of institutional decision-making but excluded from what they described as 'higher level' decisions at regional and national levels. In this respect, the 18 case study sites show similarities to many institutions across the UK that include students' perspectives in attempts to improve educational practice as well as relationships between all stakeholders (Cross 2012; Lodge 2005; Sinclair 2004). Also, in those situations where students considered they had been listened to and direct, positive change had occurred as a result of consultation and/or their participation, the outcome was more engagement in their environment, a sense of pride in themselves and their institutions and more empathy for the barriers faced by teachers and management in improving their educational institutions. Cook-Sather (2002, 10) has suggested that through listening to students in the ways identified above, 'students feel more engaged but are also more inclined to take responsibility for their education [as] it is no longer something being done to them but rather something they do'.

However, the data also indicated tensions that existed for students in relation to, what Bragg $(2007,356)$ considered, the 'sham' of consultation. While students indicated areas of positive engagement regarding aspects of 'student voice', they were also clear about the tokenistic nature of some consultation activities and their institutions' 'surface compliance' with such approaches (Rudduck and Fielding 2006, 219). In these situations, students considered that they were only being 'half listened to' and that they really did not have 'that much power' when it came to affecting change. Ultimately, such reflections suggest caution against the optimistic and relatively unquestioning approaches to voice that ignore the ever-present power relations between adults and young people in schools /colleges and the glossy popularity of consultation (Bragg 2007; Rudduck and Fielding 2006) that maintains it as a restricted and organisational construct (Fleming 2012) and oversimplifies a complex process to the detriment of the quality of outcomes.

Indeed, we are reminded that if engagement with 'student voice' is to succeed, then Cook-Sather's (2006) 'cultural shift' needs to take place that authenticates the processes of 
consultation and participation so that they seem credible and meaningful to students. Sinclair (2004) has indicated how such a 'cultural shift' might happen through the firm embedding of students' participation within core organisational structures and cultures of decision-making. Examples of such embedding might see the implementation of processes that seek, not only to invite, but normalise more informed dialogue between students and teachers/managers to realign the balance of power and ultimately challenge in constructive ways, the sharing of authority about educational matters in both low- and high-risk areas (Cook-Sather, 2009; Evan 2009).

From the data, a sense of disempowerment amongst students seemed to emerge in relation to influencing 'higher level decisions' in such areas as qualifications and examinations, within the national context. Students expressed a sense of incredulity that government would ever seek their views on the reform of national qualifications systems. However, when asked about these issues specifically, students were able to articulate clear tensions with respect to their optimum model for the structure and design of qualifications systems alongside the amount of assessment that they experienced during their school careers. Furthermore, students expressed concern with regard to how their achievements were being (de)valued, especially in relation to the currency of different qualifications; higher grades required for university entrance and jobs; and how ultimately they were the ones most affected if qualifications systems failed due to syllabus and grading changes during examination cycles.

Their views around models and design of qualifications, as well as how they are valued, seem to be at odds with what is being promoted by current government agendas for rigorous and robust qualifications (DfE 20I3b). While consultations have been conducted on reforms to examinations at 16 and 18 years (DfE 2012; Ofqual 20I2), there has been a lack of planned engagement with young people to contribute constructively to the changes proposed. A significant suggestion by students as a way forward was that teachers could be 'enablers of students' voices', to support them in having their views heard by significant stakeholders in qualification policy arenas. The main relationships sustained between awarding organisations and schools have always been through teachers as adopters of syllabuses and associated professional support. This gateway would allow teachers, in constructive dialogue with awarding bodies, to enable their students' voices to be heard. Such influence would be initially direct with those whose responsibilities are the formation and implementation of new qualifications specifications but ultimately indirect as awarding organisation personnel aim to influence government to adopt best practice with regard to design and structure of qualifications.

Students make a powerful point about teachers as enablers of their voices, yet this denotes any power they may have to influence decision-makers as being dependent on the advocacy of other stakeholders (Lundy and McEvoy 2009). Furthermore, imposition of a raft of educational policy initiatives being pressed upon schools, colleges, teachers and students all at the same time would seem to run counter to enabling teachers to actively embrace such a role. For direct power and influence of students' views on qualifications reform, Cook-Sather's 'cultural shift' (2006) needs to also occur within awarding organisations. For this to happen, awarding organisations need to actively support and organisationally embed the consultation and participation of young people's views, across diverse groups and contexts, within their deliberations about operational and qualifications change as well as listen constructively and to show how and if action has taken place based on these views as appropriate. Such a cultural shift would enable a more constructive way of these awarding organisations to continue to meet their responsibilities under the public sector equality duty (Equality Act 
2010) which obliges public or private bodies when exercising public functions to have due regard to achieve certain equality objectives and to advance equality of opportunity.

If this 'cultural shift' does not take place, then students will be left 'voiceless' in relation to some of the most significant changes to qualifications reform across the UK for some time. 'Voicelessness' in this context means that their salience as stakeholders (Mitchell, Angle, and Wood 1997) will be limited; it is not that they will not have a voice, more that their views will not be meaningfully sought and that more importantly, their power to influence will be restricted. This 'voicelessness' will seem more marked for young people within a growing context of what Brown, Lauder and Ashton (2011, I35 and 139) have called the 'social congestion' around increased competition for university places, employment and future careers. While those responsible for the national systems of examinations across the UK are forming, breaking and changing policy commitments in a pursuit of ideological and political agendas, students will suffer the indignities of the fallout that such policy disintegration will create yet their claims as equal stakeholders will not be afforded a high priority (Lundy and McEvoy 2009); the impact of which cannot be underestimated. Building students' perspectives and participation into the formation of emerging qualifications policies, either through their teachers, but preferably with them directly, will enable quality educational provision within qualifications to be realised. By authorising student voice in this area, policymakers and qualifications developers must be prepared to share authority about examination and assessment matters with students and to rethink who is authoritative about these aspects of educational life.

\section{Notes}

I. New reforms for GCSE and A Level will involve: a move back to linear examinations (taking all examination components at the end of the course); HEl involvement in A level specification development; reforming the AS qualification and its link with A level; increasing the difficulty of subject content and by extension questions on GCSE and A level papers; removal of re-sit opportunities in course and the removal of coursework and/or controlled assessment.

2. The implementation of the Education Bill (20II) saw the dissolution of a large number of educational advisory bodies. QCDA was the biggest and most significant body to be closed under this action. As a consequence, QCDA terminated a number of research contracts the project being reported on here was one of them. As a consequence, one year of a five year study was completed and reported on to QCDA in January 2011.

\section{Notes on contributor}

Jannette Elwood is a professor of Education and the director of the Doctoral Research Centre, School of Education, Queen's University, Belfast. She has worked in educational research, teaching and policy across a range of organisations. Her research interests are in the social construction and consequences of examinations and assessment practices. She was co-director, with Jo-Anne Baird, of the Centre Research (CReSt) Study.

\section{References}

Baird, J., J. Elwood, G. Duffy, A. Feiler, A. O'Boyle, J. Rose, and G. Stobart. 20II. 14-19 Centre Research Study: Educational Reforms in Schools and Colleges in England Annual Report. London: QCDA.

BBC. 2012. 'Tougher GCSE' to be Unveiled by Gove and Clegg. 17th September 2012. http://www.bbc.co. uk/news/education.

Bragg, S. 2007. "'Student Voice' and Governmentality: The Production of Enterprising Subjects?" Discourse: Studies in the Cultural Politics of Education 28 (3): 343-358.

Brown, P., H. Lauder, and D. Ashton. 20II. The Global Auction. Oxford: Oxford University Press. 
Cook, D. 2002. "Consultation for a Change? Engaging Users and Communities in the Policy Process." Social Policy and Administration 36 (5): 516-53I.

Cook-Sather, A. 2002. "Authorizing Students' Perspectives: Towards Trust, Dialogue and Change in Education." Educational Researcher 3I (4): 3-I4.

Cook-Sather, A. 2006. "Sound, Presence, and Power: 'Student Voice' in Educational Research and Reform." Curriculum Enquiry 34 (4): 359-390.

Cook-Sather, A. ed. 2009. Learning from the Student's Perspective: A Source Book for Effective Teaching. Boulder, CO: Paradigm.

Cross, B. 2012. "How does Community Matter? Misrecognition and the Participation Agenda for Children in Socially Disadvantaged Communities." Ethnography and Education 7 (3): 31 I-326.

Department of Children, Schools and Families (DCSF). 2008. Delivering 14-19 Reform: Next Steps. Nottingham: DCSF Publications.

Department of Education (DfE). 2012. Reforming Key Stage 4 Qualifications. 3Ist October 20I2. http:// www.education.gov.uk/aboutdfe/departmentalinformation/consultations/a002 13902/reforming-keystage-4-qualifications.

Department of Education (DfE). 2013a. Education Act. 28th February 2013. http://www.publications.parliament.uk/pa/bills/lbill/20 I0-20 I2/0067/lbill_20I0-20I20067_en_I.htm.

Department of Education (DfE). 20I3b. Reforming Key Stage 4 Qualifications Government Response. 2Ist February 2012. https://www.education.gov.uk/schools/teachingandlearning/qualifications/gcses/ a00221366/gcse-reform.

Elwood, J. 2012. "Qualifications, Examinations and Assessment: Views and Perspectives of Students in the 14-19 Phase on Policy and Practice." Cambridge Journal of Education 42 (4): 497-5। 2.

Elwood, J., and L. Lundy. 20I0. "Revisioning Assessment through a Children's Rights Approach: Implications for Policy, Process and Practice." Research Papers in Education 25 (3): 335-353.

Equality Act. 2010. 28th February 2013. http://www.homeoffice.gov.uk/equalities/equality-act/.

Evan, P. 2009. "Student Voice on a High-School Decision-Making Team." In Learning from the Student's Perspective: A Source Book for Effective Teaching, edited by A. Cook-Sather, 162-175. Boulder, CO: Paradigm.

Fleming, J. 2012. Young People's Participation - Where Next? Children and Society, Early View Article first published online: 20 APR 2012 doi: I 0. I I I/j. I099-0860.20 I2.00442.x.

Flutter, J., and J. Rudduck. 2004. Consulting Pupils: What's in it for Schools? London: RoutledgeFalmer.

Gibb, N. 2010. Government Announces Changes to Qualifications and the Curriculum. 22nd April 201I. www.education.gov.uk//61019/qualificationsandlearning/a0061424.

Gorard, S., A. Briggs, I. Hall, J. Lumby, F. Maringe, M. Morrison, B. Huat See, R. Shaheen, and S. Wright. 2008. National Report on the 14-19 Reform Programme: Baseline of Evidence 2007-08. London: QCDA.

Halsey, K., J. Murfield, J. Harland, and P. Lord. 2006. The Voice of Young People: An Engine for Improvement? Scoping the Evidence. National Foundation for Educational Research. http://www.cfbt.com/evidenceforeducation/PDF/91I5I_VoiceOfYoungPeople_Summary.pdf.

Harris, N. 2009. "Playing Catch-up in the Schoolyard? Children and Young People's 'Voice' and Education Rights." International Journal of Law, Policy and the Family 23 (I): 33 I-366.

Highman, J., and D. Yeomans. 20II. "Thirty Years of 14-19 Education and Training in England: Reflections on Policy, Curriculum and Organization." London Review of Education 9 (2): 217-230.

Hodgson, A., and K. Spours. 2003. Beyond A Levels: Curriculum 2000 and the Reforms of 14-19 Qualifications. London: Kogan Page.

Hodgson, A., and K. Spours. 20I la. "Educating 14- to 19-Year-Olds in England: A UK Lens on Possible Futures." London Review of Education 9 (2): 259-270.

Hodgson, A., and K. Spours. 20I lb. "Editorial - Policy for the Education and Training of 14- to 19Year-Olds in the UK - New Uncertainties and New Divisions?" London Review of Education 9 (2): $|45-15|$.

House of Commons - Children, Schools and Families Committee (HoC). 2008. Testing and Assessment: Third Report of Session 2007-08 - Volume I, HC 169-I. London: The Stationery Office.

House of Commons Education Committee ( $\mathrm{HoC})$. 2012. The Administration of Examinations for 15-19 Year Olds in England: First Report of Session 2012-13 Volume I HCI4I-I. London: The Stationery Office.

Lodge, C. 2005. "From Hearing Voices to Engaging in Dialogue: Problematising Student Involvement in School Improvement." Journal of Educational Change 6 (2): I25-I46. 
Lundy, L. 2007. "Voice is not Enough: Conceptualizing Article 12 of the United Nations Convention on the Rights of the Child." British Educational Research Journal 33 (6): 927-942.

Lundy, L., and L. McEvoy. 2009. "Developing Outcomes for Educational Services: A Children's Rightsbased Approach." Effective Education I (I): 43-60.

Middleton, E. 2006. "Youth Participation in the UK: Bureaucratic Disaster or Triumph of Child Rights." Children, Youth and Environments 16 (2): 181-190.

Mitchell, R., B. Angle, and D. Wood. 1997. "Toward a Theory of Stakeholder Identification and Salience: Defining the Principle of Who and What Really Counts." Academy of Management Review 22 (4): 853-886.

Ofqual. 2012. A Level Reform Consultation. 31st October 2012. http://www.ofqual.gov.uk/qualificationsand-assessments/qualification-reform/a-level-reform/.

Osler, A. 2010. Students' Perspectives on Schooling. London: McGraw Hill.

Payne, L. 2012. Personal Communication.

QCDA. 2009. How can Curriculum Innovation Help Increase Participation and Engagement?: QCDA Probe 4 Final Report. Coventry: QCDA.

Rudduck, J., and M. Fielding. 2006. "Student Voice and the Perils of Popularity." Educational Review 58 (2): $219-231$.

Sinclair, R. 2004. "Participation in Practice: Making it Meaningful, Effective and Sustainable." Children and Society 18 (2): 106-118.

Tisdall, K. 2008. "Is the Honeymoon Over? Children and Young People's Participation in Public Decision Making." International Journal of Children's Rights 16 (3): 419-429.

Tisdall, K., and M. Davis. 2004. "Making a Difference? Bringing Children's and Young People's Views into Policy-Making." Children and Society I8 (2): |3|-|42.

Wolf, A. 20II. Review of Vocational Education: The Wolf Report. London: DfE. 